\title{
Can a Ketone be More Reactive than an Aldehyde? Catalytic Asymmetric Synthesis of Substituted Tetrahydrofurans
}

\author{
Sunggi Lee, Han Yong Bae, and Benjamin List ${ }^{\star}$ \\ Max-Planck-Institut für Kohlenforschung, Kaiser-Wilhelm-Platz 1, 45470 Mülheim an der Ruhr, Germany. \\ *Correspondence to: list@kofo.mpg.de
}

\begin{abstract}
O-heterocycles bearing tetrasubstituted stereogenic centers are prepared via catalytic chemo- and enantioselective nucleophilic additions to ketoaldehydes, in which the ketone reacts preferentially over the aldehyde. 5and 6-membered rings with both aromatic and aliphatic substituents, as well as an alkynyl substituent, are obtained. Moreover, 2,2,5-trisubstitued and 2,2,5,5-tetrasubstituted tetrahydrofurans were synthesized with excellent stereoselectivities. Additionally, the synthetic utility of the described method has been demonstrated with a three-step synthesis of the side chain of anhydroharringtonine.
\end{abstract}

Aldehydes are generally more electrophilic and therefore more reactive toward nucleophilic additions than ketones. ${ }^{[1]}$ This is also true with ketoaldehydes, in which the aldehydic functional group typically reacts preferentially with a nucleophile. ${ }^{[2]}$ However the question arises if this tendency can be reversed upon Lewis acid activation. ${ }^{[3]}$ In this case, the ketone may react first with an external nucleophile, either because it is preferentially activated by the Lewis acid or, as has been suggested by Molander, ${ }^{[4]}$ by virtue of a neighboring group participation. Within the context of our program on asymmetric Lewis acid catalysis with a silylium ion equivalent/chiral anion pair (Si-ACDC), ${ }^{[5]}$ we became interested in exploring this type of reactivity. Specifically, we were keen on developing methodology in which ketoaldehydes undergo asymmetric Lewis acid catalyzed $\mathrm{C}-\mathrm{C}$ bond forming cyclization reactions that are accomplished by preferential nucleophilic addition to the activated ketone (Scheme 1). Here we report the fruition of these studies with the development of a broadly applicable catalytic and enantioselective approach to highly substituted tetrahydrofurans (THFs) from the corresponding 1,4ketoaldehydes.

Tetrahydrofurans are frequently appearing structures in natural products and biologically active molecules. ${ }^{[6]}$ Consequently, numerous methods have been developed for the enantioselective construction of these important heterocycles. ${ }^{[7]}$ However, there is a limited number of synthetic methods that provide 2,2-disubstituted analogs with tetrasubstituted steterogenic centers, despite the known biological potency of this motif against multiple targets. ${ }^{[8]}$ In fact, only a few methods aiming at such targets have been reported including oxidative Wacker-type cyclizations, ${ }^{[9]}$ carboalkoxylations, ${ }^{[10]}$ an hydroalkoxylation, ${ }^{[11]}$ and others. ${ }^{[12]}$ In most cases, the stereoselective preparation of the starting tri- and tetrasubstituted olefins is considered the major limitation.

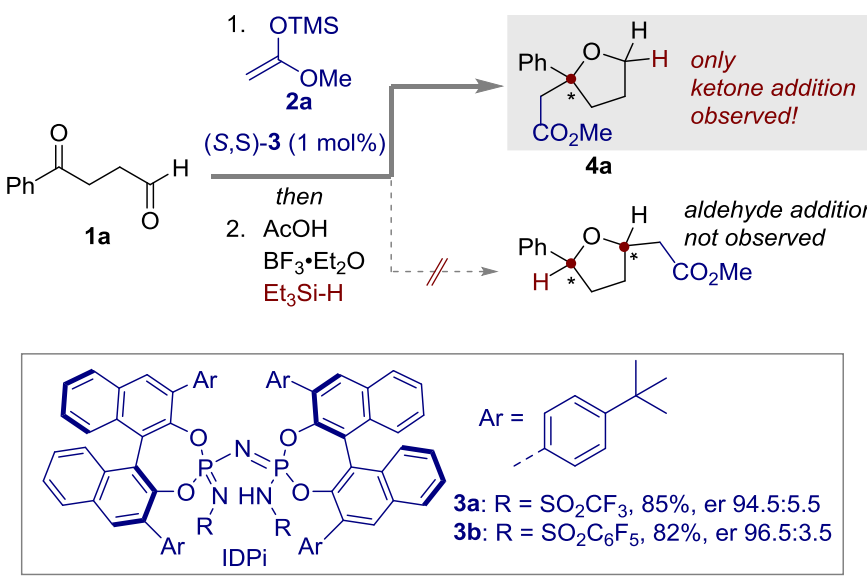

Scheme 1. Initial observations of nucleophilic addition of $2 a$ to ketoaldehyde 1a catalysed by IDPi 3

Recently, the Watson group reported an alkynylation of 2aryl substituted cyclic oxocarbenium ions using a $\mathrm{Cu}(\mathrm{I})$ complex for the synthesis of diaryl, tetrasubstituted stereogenic centers. ${ }^{[13]}$ Though cyclic oxocarbenium ions are extensively exploited in glycosylations and natural product syntheses, their application in asymmetric synthesis is scarce. ${ }^{[14]}$ This mainly originates from their capricious stability, which largely depends on the amount and size of substituents, as well as the absence of a strong coordinating site. Following our first success on the enantioselective functionalization of in situ generated cyclic oxocarbenium ions, ${ }^{[14 q]}$ we envisioned that imidodiphosphorimidates (IDPis) $^{[11,14 q, 15]}$ would be efficient catalysts for the formation of tetrasubstituted stereogenic centers by controlling stereochemically more challenging, yet more stable, 2- 
Table 1. Substrate scope using ketoaldehydes. ${ }^{[a]}$

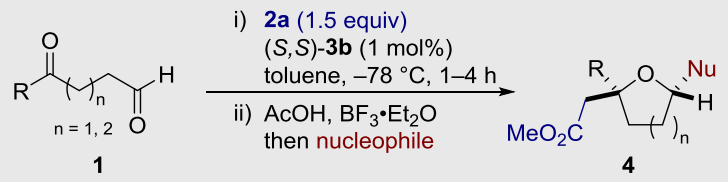

(A) using $\mathrm{Et}_{3} \mathrm{Si}-\mathrm{H}$

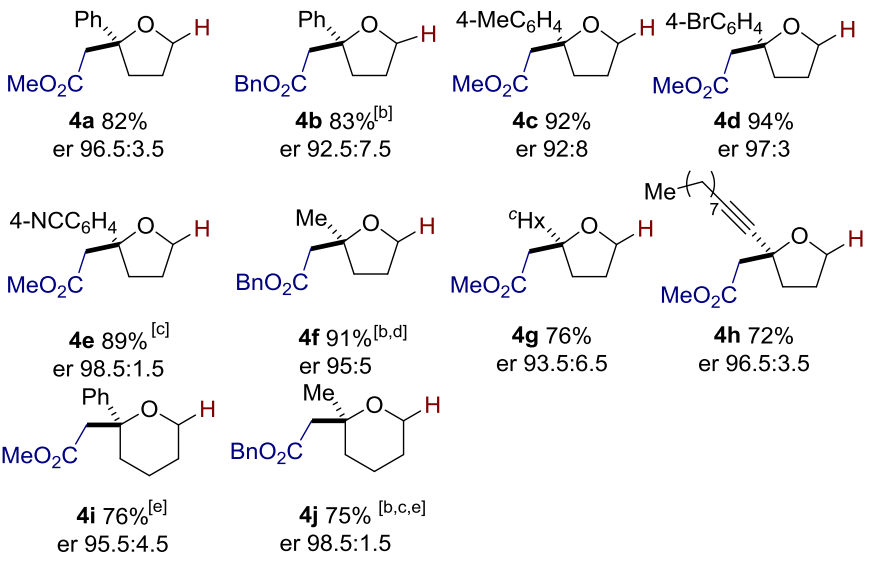

(B) using other nucleophiles (see footnote)<smiles>C=CC[C@H]1CCC(CCOC)(c2ccccc2)O1</smiles>

$4 \mathbf{k} 80 \%$

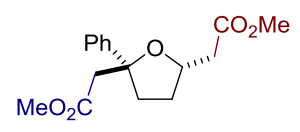

$4183 \%$ dr $12.6: 1$ er $96: 4$

dr $4.1: 1$ er $96.5: 3.5$

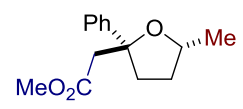

$4 \mathrm{~m} 58 \%$,
(C) Chemo-, diastereo-, and enantioselective synthesis using $2 c$<smiles>O=CCCC(=O)c1ccccc1</smiles>

$1 \mathrm{a}$

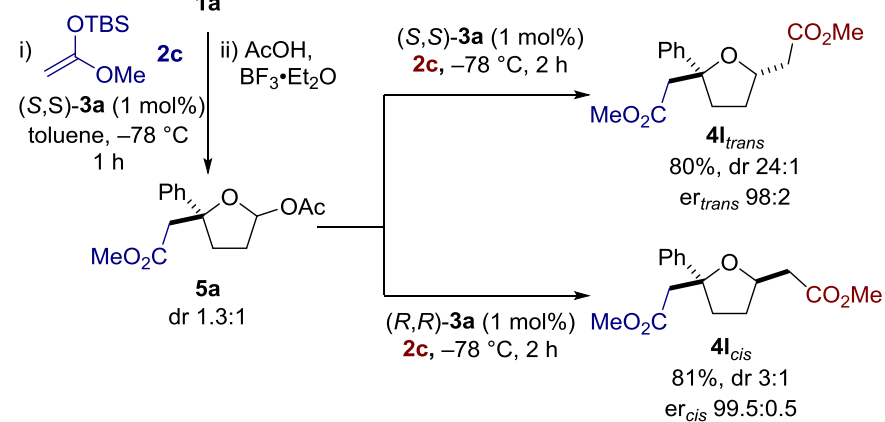

[a] Reactions were conducted with substrate $\mathbf{1}(0.2 \mathrm{mmol}, 1.0$ equiv), $\mathbf{2 a}(0.3$ mmol, 1.5 equiv), and catalyst $3 \mathrm{~b}(1.0 \mathrm{~mol} \%)$ in toluene $(0.1 \mathrm{M})$ at $-78{ }^{\circ} \mathrm{C}$ After full consumption of starting material, 2.0 equiv of $\mathrm{AcOH}$ and 3.0 equiv of $\mathrm{BF}_{3} \cdot \mathrm{Et}_{2} \mathrm{O}$ were added, followed by addition of 3.0 equiv of the second nucleophile, i.e. $\mathrm{Et}_{3} \mathrm{SiH}$, allyltrimethylsilane, $\mathbf{2 c}$, or $\mathrm{Me}_{3} \mathrm{Al}$. For details, see the Supporting Information. [b] using 1-(trimethylsilyloxy)-1-benzyloxyethene $\mathbf{2 b}$ instead of $2 \mathrm{a}[\mathrm{c}]$ at $-40^{\circ} \mathrm{C}[\mathrm{d}]$ at $-95^{\circ} \mathrm{C}$ [e] using $(S, S)-3 \mathbf{a}$

substituted cyclic oxocarbenium ions via asymmetric counteranion directed catalysis (ACDC). ${ }^{[16]}$

To test our hypothesis, 4-oxo-4-phenylbutanal 1a was reacted with silyl ketene acetal $2 \mathbf{a}$ in toluene at $-78{ }^{\circ} \mathrm{C}$ (Scheme 1). The reaction was complete within 1 hour using only 1 mol\% of $(S, S)$-IDPi $\mathbf{3 a}$ and gave product $\mathbf{4 a}$ in $94.5: 5.5$ er with in situ reduction of the acetal intermediate. ${ }^{[17]}$
Remarkably, only the product resulting from the attack of the nucleophile on the ketone was observed. Similar to our previous findings on the catalyst design, ${ }^{[11]}$ modifying the electron withdrawing group of the sulfonamide from a $\mathrm{CF}_{3}$ group to more sterically demanding $\mathrm{C}_{6} \mathrm{~F}_{5}$ group increased the enantioselectivity to $96.5: 3.5$ with full conversion of the starting material within $1 \mathrm{~h}$ (Scheme 1).

With the optimized catalyst in hand, we investigated the reaction scope (Table 1). The steric bulk of the nucleophile could be increased without significant deterioration in yield and enantioselectivty (4b, $\mathbf{4 f}$, and $\mathbf{4 j}$ ). Moreover, changes in the electronic nature of phenyl ring were well tolerated $(\mathbf{4 c}$, $\mathbf{4 d}$, and $\mathbf{4 e}$ ). Both methyl and cyclohexyl ketones $\mathbf{1 e}$ and $\mathbf{1 f}$ showed excellent chemo- and enantioselectivities, as well as alkynyl ketone 1g. Gratifyingly, when 5-ketoaldehydes were employed, tetrahydropyrans with a tetrasubstituted stereogenic center (4i and $\mathbf{4} \mathbf{j}$ ) were obtained in high yields and enantioselectivities.

The introduction of carbon nucleophiles in the second step provides a useful procedure to generate 2,2,5-trisubstituted tetrahydrofuran rings, which occasionally appear in natura products (Table 1B). Allylation and alkylations using silylated nucleophiles, such as allyltrimethylsilane and silyl ketene acetal 2c, resulted in high enantioselectivities and moderate diastereoselectivities of the corresponding trisubstituted products $\mathbf{4 k}$ and $4 \mathrm{I}$. A simple methyl substitution using $\mathrm{Me}_{3} \mathrm{Al}$ was also possible, giving the same level of enantioselectivity $(4 \mathrm{~m})$.

The current method enables the selective formation of either the cis- or trans-isomer of a 2,2,5-trisubstituted tetrahydrofuran ring, overcoming the intrinsic preference (Table 1C). Namely, after the formation of TBS protected acetal using $(S, S)$-IDPi $3 \mathbf{a}$, treatment with acetic acid and $\mathrm{BF}_{3} \cdot \mathrm{Et}_{2} \mathrm{O}$ afforded lactol acetate $\mathbf{5 a}$ with moderate diastereomeric ratio (1.3:1). Remarkably, when the same enantiomer of catalyst was applied in the second $\mathrm{C}-\mathrm{C}$ bond forming step, the trans-selectivity was enhanced to $24: 1$. In sharp contrast, the other enantiomer of the catalyst, $(R, R)-\mathbf{3 a}$, furnished the cis-isomer as the major product in superb er and moderate $\mathrm{dr}$ within $2 \mathrm{~h}$.

Table 2. Substrate scope using 1,4-diketones. ${ }^{[\mathrm{a}]}$
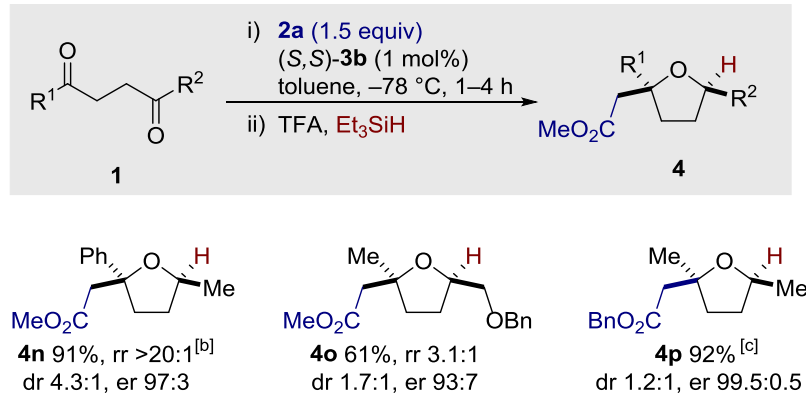

dr 1.2:1, er 99.5:0.5

[a] Reactions were conducted with 1.0 equiv of substrate $\mathbf{1}, 1.5$ equiv of 2 , and $1.0 \mathrm{~mol} \%$ catalyst 3 in toluene $(0.1 \mathrm{M})$ at $-78{ }^{\circ} \mathrm{C}$. After full consumption of starting material, 5.0 equiv of trifluoroacetic acid and 5.0 equiv of $\mathrm{Et}_{3} \mathrm{SiH}$ were added. For details, see the Supporting Information. [b] at $-95^{\circ} \mathrm{C}[\mathrm{c}]$ using $2 \mathbf{b}$ instead of $\mathbf{2 a}$ 
The differentiation between two ketones is also possible (Table 2). When 1-phenylpentane-1,4-dione $\mathbf{1 j}$ was treated with $\mathbf{2 a}$ in the presence of $1 \mathrm{~mol} \%(S, S)-3 \mathbf{a}$, a nucleophilic attack was accomplished on the side of the sterically more hindered carbonyl site, giving 97:3 enantioselectivity at $95{ }^{\circ} \mathrm{C}$, providing $4 \mathrm{n}$, a diastereomer of $4 \mathrm{~m}$. Interestingly, the regioselectivity can be altered by the substitution of a benzyloxy coordinating group, i.e. ketone $\mathbf{1 k}$ afforded the tetrasubstituted stereogenic center on the side of methyl ketone (40) with er of 93:7. Desymmetrization of a symmetric diketone, hexane-2,5-dione, could be achieved with excellent enantioselectivity, albeit with only a moderate diastereomeric ratio $(4 p)$.

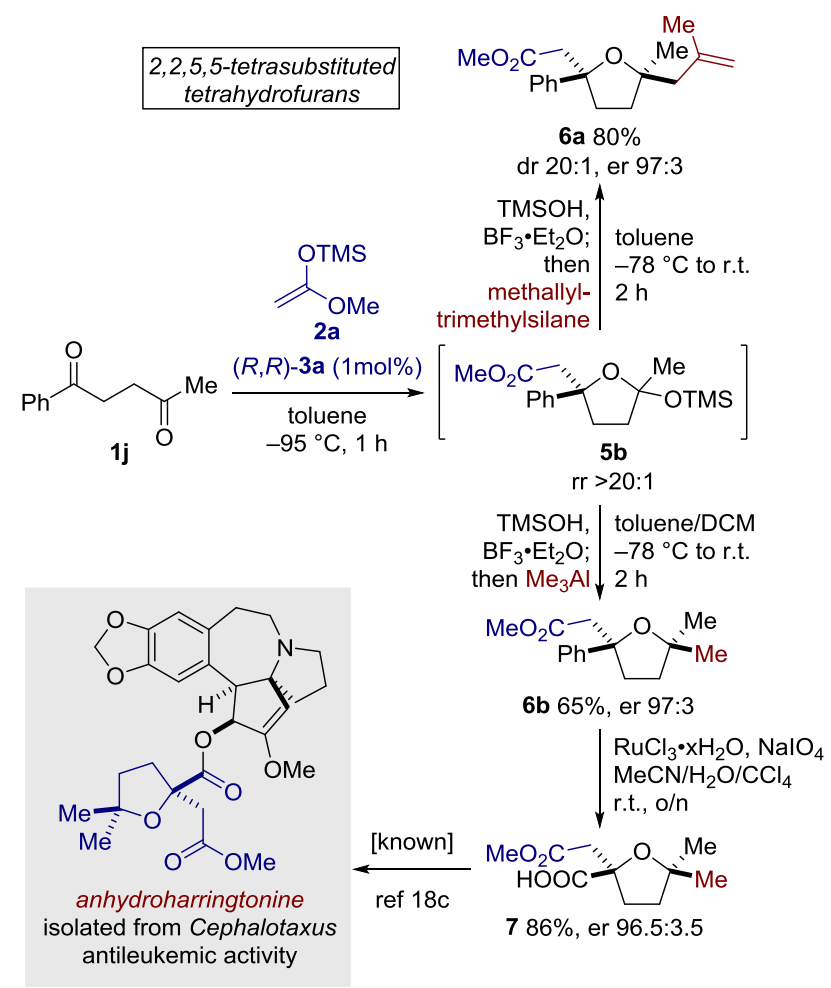

Scheme 2. Synthesis of enantioenriched 2,2,5,5-tetrasubstituted tetrahydrofurans and the side chain of anhydroharringtonine

The synthetic utility of this method can be highlighted by the straightforward preparation of enantioenriched 2,2,5,5tetrasubstutited tetrahydrofurans (Scheme 2). When intermediate $\mathbf{5 b}$, which is generated from the reaction between $1 \mathbf{j}$ and $2 \mathbf{a}$ in the presence of $1 \mathrm{~mol} \%(R, R)-3 \mathbf{a}$ at $95^{\circ} \mathrm{C}$, was reacted further with methylallyltrimethylsilane, the corresponding 0 -heterocycles 6 a were afforded with high yield and excellent regio-, diastereo- and enantioselectivity. With the same intermediate $\mathbf{5 b}$, the side chain of anhydroharrintonine ${ }^{[18]}$ which is isolated from the genus Cephalotaxus and known for antileukemic activity, was synthesized. A methylation of $\mathbf{5 b}$ using trimethylaluminum, followed by catalytic oxidation of phenyl group using $\mathrm{RuCl}_{3} \cdot \mathrm{xH}_{2} \mathrm{O}$, allowed us to obtain the corresponding acid 7 in three steps.

To gain insight on the reaction mechanism, we have investigated the reactivity of 1-phenyl-1-butanone 8 and pentanal 10 under the identical reaction conditions (Scheme $3 A$ ). Interestingly, only $5 \%$ of product $\mathbf{1 1}$ was observed when aldehyde 10 was used as starting material, while no desired aldol adduct was observed using ketone $\mathbf{8}^{[19]}$ In addition, an equal molar mixture of ketone $\mathbf{8}$ and aldehyde $\mathbf{1 0}$ gave the same low conversion. These results contrast with the full conversion of ketoaldehyde $\mathbf{1 a}$ and clearly imply that dicarbonyl structures are essential in our reactions and the highly reactive cyclic oxocarbenium ions are involved. Our results also suggest that the reaction does not precede through the direct nucleophilic addition of the silyl ketene acetals onto ketones which can generate the same products by sequential cyclization of silyl ether towards aldehydes. Based on these observations, we propose the following mechanism. First, the in situ formed silylium ion pair catalyst coordinates to the sterically less hindered aldehyde $(\mathbf{A})$, and invokes an intramolecular cyclization to afford a highly active cyclic oxocarbenium ion intermediate $\mathbf{B}$ (Scheme 3B). At this point, the counteranion of IDPi $\mathbf{3}$ can direct the approach of external nucleophiles by discriminating the enantiofaces of a multisubstituted cyclic aliphatic oxocarbenium ion. Subsequently, formation of the highly substituted heterocycle $\mathbf{C}$ and regeneration of the silylium ion pair complete the catalytic cycle.

(A)

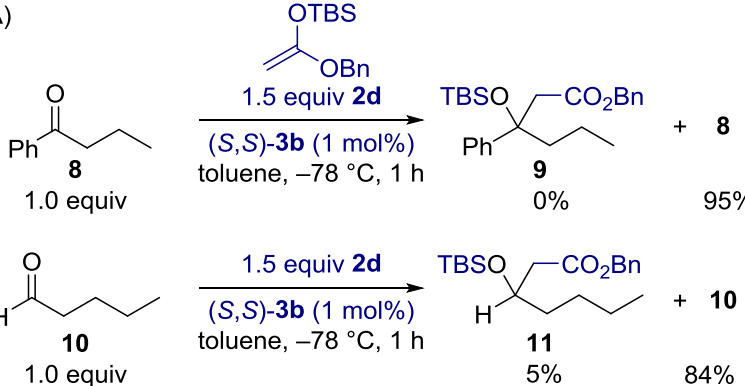

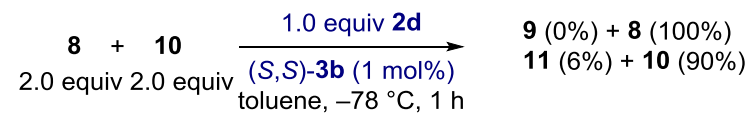

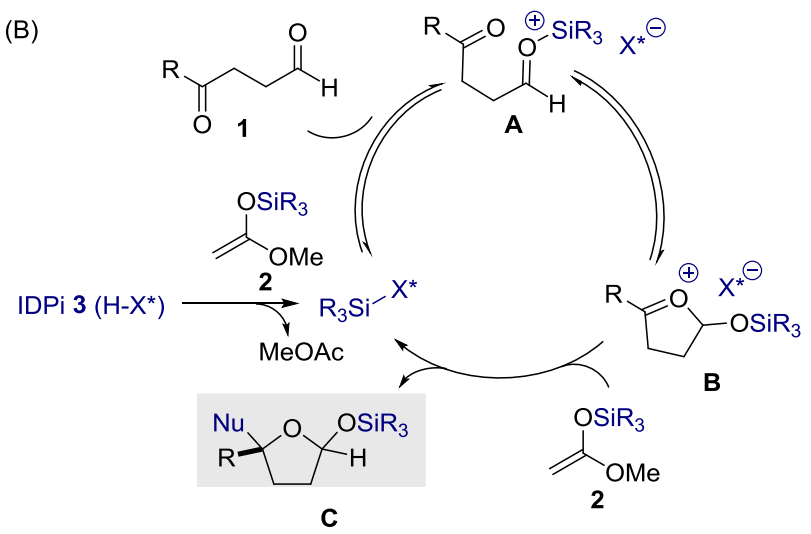

Scheme 3. (A) Reactivity comparison between aldehyde and ketone (B) Plausible catalytic cycle

In conclusion, we have developed a regio- and enantioselective catalytic method which affords highly substituted tetrahydrofurans and tetrahydropyrans starting from 1,4- and 1,5-dicarbonyl compounds using IDPis as 
catalysts. The selective addition of nucleophiles toward ketones over aldehydes was observed. The efficiency of the method was demonstrated by the chemo-, diastereo- and enantioselective construction of 2,2,5-trisubsituted furans. Moreover, 2,2,5,5-tetrasubstituted tetrahydrofurans can be readily synthesized using the described method.

\section{Acknowledgements}

Generous support from the Max Planck Society, the Deutsche Forschungsgemeinschaft (Leibniz Award to B.L. and Cluster of Excellence RESOLV, EXC 1069), and the European Research Council (Advanced Grant "C-H Acids for Organic Synthesis, CHAOS") are gratefully acknowledged. We thank the technicians of our group, and the members of our NMR, MS, GC and HPLC departments for their excellent service.

Keywords: enantioselective nucleophilic addition, silylium Lewis acid catalysis, imidodiphosphorimidates, $\mathrm{O}$ heterocycles, tetrasubstituted stereogenic centers

[1] P. Vollhardt, N. Schore, Organic Chemistry: Structure and Function, 8th ed. 2018 edition ed., WH Freeman, 2018, chapter 17.

[2] For selected exapmes, see: a) G. A Molander, S. W. Andrews, Tetrahedron Lett. 1989, 30, 2351-2354; b) X. Lu, G. Guo, D. Ma, J. Org. Chem. 1991, 56, 6712-6715; c) M. Watanabe, K. Soai, J. Chem. Soc. Perkin Trans. 1 1994, 3125-3128; d) K. Okada, K. Matsumoto, K Oshima, K. Utimoto, Tetrahedron Lett. 1995, 36, 8067-8070; e) M. J. Campbell, J. S. Johnson, J. Am. Chem. Soc. 2009, 131, 10370 10371 ;) S. Chandrasekhar, A. Shrinidhi, Synth. Commun. 2014, 44 2051-2056.

[3] a) J.-x. Chen, J. Otera, Tetrahedron Lett. 1998, 1767-1770; b) J.-x. Chen, K. Sakamoto, A. Orita, J. Otera, J. Org. Chem. 1998, 63, 9739 9745; c) N. Asao, T. Asano, Y. Yamamoto, Angew. Chem. Int. Ed. 2001 40, 3206-3208; d) D. Nakashima, H. Yamamoto, Org. Lett. 2005, 7 1251-1253.

[4] a) G. A. Molander, K. O. Cameron, J. Org Chem. 1991, 56, 2617 2619; b) G. A. Molander, K. O. Cameron, J. Am. Chem. Soc. 1993, 115 830-846; c) G. A. Molander, P. R. Eastwood, J. Org. Chem. 1996, 61 1910-1911; d) G. A. Molander, J. Haas, Tetrahedron 1999, 55, 617624.

[5] a) P. García-García, F. Lay, P. García-García, C. Rabalakos, B. List, Angew. Chem. Int. Ed. 2009, 48, 4363-4366; b) L. Ratjen, P. GarcíaGarcía, F. Lay, M. E. Beck, B. List, Angew. Chem. Int. Ed. 2011, 50 754-758; c) J. Guin, C. Rabalakos, B. List, Angew. Chem. Int. Ed. 2012 51, 8859-8863; d) M. Mahlau, P. García-García, B. List, Chem. Eur. J. 2012, 18, 16283-16287; e) S. Gandhi, B. List, Angew. Chem. Int. Ed. 2013, 52, 2573-2576; f) Q. Wang, M. Leutzsch, M. van Gemmeren, B. List, J. Am. Chem. Soc. 2013, 135, 15334-15337; g) J. Guin, Q. Wang M. van Gemmeren, B. List, Angew. Chem. Int. Ed. 2014, 54, 355-358; h) L. Ratjen, M. van Gemmeren, F. Pesciaioli, B. List, Angew. Chem. Int Ed. 2014, 53, 8765-8769; i) Q. Wang, M. van Gemmeren, B. List Angew. Chem. Int. Ed. 2014, 53, 13592-13595; j) T. Gatzenmeier, M van Gemmeren, Y. Xie, D. Hofler, M. Leutzsch, B. List, Science 2016. 351, 949-952; k) A. Tap, A. Blond, V. N. Wakchaure, B. List, Angew. Chem. Int. Ed. 2016, 55, 8962-8965; I) Z. Zhang, H. Y. Bae, J. Guin, C Rabalakos, M. van Gemmeren, M. Leutzsch, M. Klussmann, B. List Nat. Commun. 2016, 7, 12478.

[6] a) M. M. Faul, B. E. Huff, Chem. Rev 2000, 100, 2407-2474; b) E. J. Kang, E. Lee, Chem. Rev. 2005, 105, 4348-4378; c) A. Lorente, J. Lamariano-Merketegi, F. Albericio, M. Alvarez, Chem. Rev. 2013, 113 4567-4610.

[7] a) P. A. Clarke, S. Santos, Eur. J. Org. Chem. 2006, 2006, 2045-2053; b) J. P. Wolfe, M. B. Hay, Tetrahedron 2007, 63, 261-290; c) I. Larrosa P. Romea, F. Urpí, Tetrahedron 2008, 64, 2683-2723; d) G. Jalce, X.
Franck, B. Figadère, Tetrahedron: Asymmetry 2009, 20, 2537-2581; e) C. F. Nising, S. Bräse, Chem Soc Rev 2012, 41, 988-999; f) N. M. Nasir, K. Ermanis, P. A. Clarke, Org. Biomol. Chem. 2014, 12, 33233335; g) A. de la Torre, C. Cuyamendous, V. Bultel-Poncé, T. Durand J.-M. Galano, C. Oger, Tetrahedron 2016, 72, 5003-5025; h) F. Vetica, P. Chauhan, S. Dochain, D. Enders, Chem. Soc. Rev. 2017, 46, 16611674.

[8] a) W. J. Houlihan, M. L. Lee, P. G. Munder, G. M. Nemecek, D. A Handley, C. M. Winslow, J. Happy, C. Jaeggi, Lipids 1987, 22, 884 890 ; b) C. M. Lee, L. M. Jiang, H. S. Shang, P. M. Hon, Y. He, H. N Wong, Br. J. Pharmacol. 1991, 103, 1719-1724; c) G. A. Doherty, G. X Yang, E. Borges, L. L. Chang, M. MacCoss, S. Tong, U. Kidambi, L. A Egger, E. McCauley, G. Van Riper, R. A. Mumford, J. A. Schmidt, W. K. Hagmann, Bioorg. Med. Chem. Lett. 2002, 12, 1501-1505.

[9] a) Y. Uozumi, H. Kyota, K. Kato, M. Ogasawara, T. Hayashi, J. Org. Chem. 1999, 64, 1620-1625; b) R. M. Trend, Y. K. Ramtohul, E. M. Ferreira, B. M. Stoltz, Angew. Chem. Int. Ed. 2003, 42, 2892-2895; c) F. Wang, Y. J. Zhang, G. Yang, W. Zhang, Tetrahedron Lett. 2007, 48, 4179-4182; d) Y. J. Zhang, F. Wang, W. Zhang, J. Org. Chem. 2007 72, 9208-9213.

[10] a) B. A. Hopkins, Z. J. Garlets, J. P. Wolfe, Angew. Chem. Int. Ed. 2015 54, 13390-13392; b) N. Hu, K. Li, Z. Wang, W. Tang, Angew. Chem. Int. Ed. 2016, 55, 5044-5048; c) Y.-F. Cheng, X.-Y. Dong, Q.-S. Gu, Z.-L. Yu, X.-Y. Liu, Angew. Chem. Int. Ed. 2017, 56, 8883-8886.

[11] N. Tsuji, J. L. Kennemur, T. Buyck, S. Lee, S. Prevost, P. S. J. Kaib, D. Bykov, C. Fares, B. List, Science 2018, 359, 1501-1505.

[12] a) S. H. Kang, C. M. Park, S. B. Lee, M. Kim, Synlett 2004, 2004 1279-1281; b) Z. Ke, C. K. Tan, F. Chen, Y.-Y. Yeung, J. Am. Chem. Soc. 2014, 136, 5627-5630; c) Z. Ke, C. K. Tan, Y. Liu, K. G. Z. Lee, Y.-Y. Yeung, Tetrahedron 2016, 72, 2683-2689. d) J. Y. See, H. Yang Y. Zhao, M. W. Wong, Z. Ke, Y.-Y. Yeung, ACS Catal. 2018, 8, 850-858

[13] S. Dasgupta, T. Rivas, M. P. Watson, Angew. Chem. Int. Ed. 2015, 54, 14154-14158

[14] a) M. Braun, W. Kotter, Angew. Chem. Int. Ed. 2004, 43, 514-517; b) S. E. Reisman, A. G. Doyle, E. N. Jacobsen, J. Am. Chem. Soc. 2008, 130 , 7198-7199; c) F. Benfatti, E. Benedetto, P. G. Cozzi, Chem. Asian. J. 2010, 5, 2047-2052; d) P. N. Moquist, T. Kodama, S. E. Schaus, Angew. Chem. Int. Ed. 2010, 49, 7096-7100; e) N. Z. Burns, M. R. Witten, E. N. Jacobsen, J. Am. Chem. Soc. 2011, 133, 14578-14581; f) P. Maity, H. D. Srinivas, M. P. Watson, J. Am. Chem. Soc. 2011, 133, 17142-17145; g) M. Rueping, C. M. R. Volla, I. Atodiresei, Org. Lett. 2012, 14, 4642-4645; h) M. P. Watson, P. Maity, Synlett 2012, 23 , 1705-1708; i) Y. Cui, L. A. Villafane, D. J. Clausen, P. E. Floreancig, Tetrahedron 2013, 69, 7618-7626; j) C.-C. Hsiao, H.-H. Liao, E. Sugiono, I. Atodiresei, M. Rueping, Chem. Eur. J. 2013, 19, 97759779; k) M. Terada, T. Yamanaka, Y. Toda, Chem. Eur. J. 2013, 19, 13658-13662; I) Z. Meng, S. Sun, H. Yuan, H. Lou, L. Liu, Angew. Chem. Int. Ed. 2014, 53, 543-547; m) M. Terada, F. Li, Y. Toda, Angew. Chem. Int. Ed. 2014, 53, 235-239; n) H. D. Srinivas, P. Maity, G. P. A Yap, M. P. Watson, J. Org. Chem. 2015, 80, 4003-4016; o) A. M. Hardman-Baldwin, M. D. Visco, J. M. Wieting, C. Stern, S.-i. Kondo, A. E. Mattson, Org. Lett. 2016, 18, 3766-3769; p) Z. Yang, Y. He, F. D. Toste, J. Am. Chem. Soc. 2016, 138, 9775-9778; q) S. Lee, P. S. J. Kaib, B. List, J. Am. Chem. Soc. 2017, 139, 2156-2159.

[15] a) P. S. J. Kaib, L. Schreyer, S. Lee, R. Properzi, B. List, Angew. Chem. Int. Ed. 2016; b) Y. Xie, G.-J. Cheng, S. Lee, P. S. J. Kaib, W. Thiel, B. List, J. Am. Chem. Soc. 2016, 138, 14538-14541; c) L. Liu, H. Kim, Y. Xie, C. Farès, P. S. J. Kaib, R. Goddard, B. List, J. Am. Chem. Soc. 2017, 139, 13656-13659; d) T. Gatzenmeier, P. S. J. Kaib, J. B. Lingnau, R. Goddard, B. List, Angew. Chem. Int. Ed. 2018, 57, 2464 2468; e) H. Y. Bae, D. Höfler, P. S. J. Kaib, P. Kasaplar, C. K. De, A Döhring, S. Lee, K. Kaupmees, I. Leito, B. List, Nat. Chem. 2018, DOI = 10.1038/s41557-018-0065-0

[16] a) M. Mahlau, B. List, Angew. Chem. Int. Ed. 2013, 52, 518-533; b) T. James, M. van Gemmeren, B. List, Chem. Rev 2015, 115,9388-9409.

[17] a) K. Maeda, H. Shinokubo, K. Oshima, J. Org. Chem. 1997, 62, 64296431; b) S. Kanwar, S. Trehan, Tetrahedron Lett. 2005, 46, 1329-1332 c) B. Padhi, D. S. Reddy, D. K. Mohapatra, Eur. J. Org. Chem. 2015 2015, 542-547.

[18] a) R. A. Ancliff, A. T. Russell, A. J. Sanderson, Chem. Commun. 2006 3243-3245; b) J. D. Eckelbarger, J. T. Wilmot, M. T. Epperson, C. S. Thakur, D. Shum, C. Antczak, L. Tarassishin, H. Djaballah, D. Y. Gin Chem. Eur. J. 2008, 14, 4293-4306; c) F. Berhal, S. Tardy, J. PérardViret, J. Royer, Eur. J. Org. Chem. 2009, 2009, 437-443.

[19] Enantioselective Aldol reactions of ketones were reported using IDPi at higher reation temperatrue $\left(-20^{\circ} \mathrm{C}\right)$. see ref $15 \mathrm{e}$. 